\title{
Association between milk antibody and interferon-gamma responses in cattle from Mycobacterium avium subsp. paratuberculosis infected herds
}

\author{
Mikkelsen, Heidi; Jungersen, Gregers; Nielsen, Søren Saxmose
}

Published in:

Veterinary Immunology and Immunopathology

Link to article, DOI:

10.1016/j.vetimm.2008.10.315

Publication date:

2009

Link back to DTU Orbit

Citation (APA):

Mikkelsen, H., Jungersen, G., \& Nielsen, S. S. (2009). Association between milk antibody and interferon-gamma responses in cattle from Mycobacterium avium subsp. paratuberculosis infected herds. Veterinary Immunology and Immunopathology, 127(3-4), 235-241. https://doi.org/10.1016/j.vetimm.2008.10.315

\section{General rights}

Copyright and moral rights for the publications made accessible in the public portal are retained by the authors and/or other copyright owners and it is a condition of accessing publications that users recognise and abide by the legal requirements associated with these rights.

- Users may download and print one copy of any publication from the public portal for the purpose of private study or research.

- You may not further distribute the material or use it for any profit-making activity or commercial gain

- You may freely distribute the URL identifying the publication in the public portal 


\title{
Association between milk antibody and interferon-gamma responses in cattle from
}

Mycobacterium avium subsp. paratuberculosis infected herds

\author{
Heidi Mikkelsen ${ }^{1,2}$, Gregers Jungersen ${ }^{1}$ and Søren Saxmose Nielsen ${ }^{2}$
}

${ }^{1}$ Section for Immunology and Parasitology, National Veterinary Institute, Technical University of Denmark, Bülowsvej 27, DK-1790 Copenhagen, Denmark; ${ }^{2}$ Department of Large Animal Sciences, Faculty of Life Sciences, University of Copenhagen, Grønnegårdsvej 8, DK-1870 Frederiksberg C, Denmark

Corresponding author:

Heidi Mikkelsen

National Veterinary Institute

Bülowsvej 27

DK-1790 Copenhagen V

E-mail: heimi@vet.dtu.dk

Tel: +4572346634

Fax: +4572346001 


\begin{abstract}
Paratuberculosis is a chronic infection of ruminants caused by Mycobacterium avium subsp. paratuberculosis (MAP). It is possible to detect infection with paratuberculosis at different stages of disease by means of various diagnostic test strategies. The objective of the present study was to evaluate if early cell-mediated immunity could predict the antibody results of milk samples in cattle with different faecal culture (FC) status. A group of 975 cows from 18 Danish MAP infected dairy herds was studied during a three year period. Cell-mediated immunity was measured in blood samples from heifers by use of an IL-12 potentiated IFN- $\gamma$ protocol. Following calving, milk samples were collected and analysed for MAP specific antibodies by ELISA and faecal samples were cultured. The relationship between the variables IFN- $\gamma$ and FC and the outcome of ELISA was assessed using generalised additive models. The results of the study showed that a significant association exists between early IFN- $\gamma$ and later FC status with occurrence of antibodies. In addition, the early IFN- $\gamma$ and FC status affect the antibody ELISA result at different stages post calving. We observed that only some IFN- $\gamma$ positive animals developed a positive antibody response against MAP, which indicate that cell-mediated immune responses can control or eradicate MAP in many animals.
\end{abstract}

Keywords: antibodies, cell-mediated immunity, ELISA, interferon-gamma, paratuberculosis 


\section{Introduction}

Paratuberculosis is a chronic, granulomatous enteric infection caused by Mycobacterium avium subsp. paratuberculosis (MAP) in ruminants. Infection of dairy cattle leads to economic losses through premature culling and reduced milk yield (Ott et al., 1999). It is believed that cattle are largely infected as calves, either in utero or more often as neonates via ingestion of faecal matter, milk or colostrum containing the bacteria (Chiodini et al., 1984; Sweeney, 1996). Cell mediated immunity (CMI) is critical to host defence against intracellular MAP and is initially elicited at an early stage in infection where antibodies are still not detected (Chiodini, 1996; Toman et al., 2003). During disease progression from the subclinical to the clinical stage, CMI gradually wanes and a strong humoral immune response with antibody formation develops. However, antibodies do not protect the cows against progression of disease (Stabel, 2000).

An important tool for management and control of MAP is diagnostic testing to detect infectious cows that pose a potential risk to calves in the herd. Diagnosis of MAP infected animals is usually not possible before two years of age by detection of specific serum/milk antibodies or by faecal culture (FC) (Nielsen and Toft, 2006). However, measurement of the CMI by the IFN- $\gamma$ test poses an alternative, which would enable detection of infected and infectious animals at an early stage of disease.

The IFN- $\gamma$ test can be used specifically for animals older than 15 months, while analyses of IFN- $\gamma$ responses in younger animals are prone to non-specific false positive reactions (Jungersen et al., 2002). This is possibly due to activation of NK cells (Olsen et al., 2005).

A diagnostic test that can identify animals before they become infectious is desirable. To accomplish this, a highly specific diagnostic test, or refinement of the existing IFN- $\gamma$ test, should be further developed. Given the current understanding of the pathogenesis of paratuberculosis, a positive correlation between early CMI, followed by a serological response, bacteriological 
shedding and later clinical disease is expected. Therefore, our objectives were to: a) describe an IFN- $\gamma$ method using IL-12 for early detection of MAP infected animals; and b) to study early IFN- $\gamma$ to predict the antibody ELISA results of milk samples in cattle with different FC status. 


\section{Materials and methods}

\subsection{Herds and animals}

The present study included 975 cows from 18 Danish dairy herds during a period of three years through August 2003 to December 2007. The herds consisted of a non-random sample, where practising veterinarians had suggested their inclusion in a study of intervention against paratuberculosis. During the study period, two of the included herds ceased production. A brief description of the herds is given in Table 1. Information on dates of birth, dates of calving and breed was obtained from the Danish Cattle Database. The cows were distributed among 5 different breeds: 722 Danish Holstein (black and white), 47 Danish Holstein (red and white), 161 Danish Jersey, 13 Red Danish and 32 cross breed. For the duration of the study, 972 of the animals calved once and three of the animals calved twice.

\subsection{Sampling}

The study was conducted as an observational longitudinal study with a sampling frame as illustrated in Figure 1. One heparinised whole-blood sample was collected by the vacutainer system from each animal in the period 15 to 24 months of age and samples were subject to IFN- $\gamma$ testing. After first calving, annual faecal samples for detection of MAP were collected by milk quality advisors from rectum, using one glove per cow. This resulted in minimum one faecal sample per cow. Milk samples for detection of antibodies were collected 4 times per year in each herd via the Danish milk recording scheme as done in the Danish paratuberculosis control programme (Nielsen, 2007). A total of 5,545 milk ELISA results from 975 cows in 18 dairy herds was included in the study. Of these, 144 cows had less than 4 tests, 136 had 4 tests, 185 had 5 tests, 172 had 6 tests and 338 had 7 or more ELISA tests (minimum 1, median 5 and maximum 12 samples per cow). The number of ELISA samples per cow varied due to the observational design of the study; new cows entered at 
first calving, and older cows left when they were sold, culled or died. Distribution of milk samples in different age groups are given in Table 2.

\subsection{Diagnostic testing}

\subsubsection{ELISA analysis for milk antibody}

Milk samples were tested for the presence of MAP antibodies using an ELISA performed as described elsewhere (Nielsen, 2002). The ELISA is based on a commercially available antigen (Allied Monitor, Fayette, Missouri, USA) designated 'M. paratuberculosis Strain 18' and the ELISA detects both $\operatorname{IgG} 1$ and $\mathrm{IgG} 2$.

\subsubsection{Analysis for cell-mediated immunity}

One of the major impediments for using the IFN- $\gamma$ test is that the time span from collection of the blood sample to start of culture influence the viability of the cells. To obtain valuable results it is therefore recommended to start culture within 8-12 hours of sampling (Robbe-Austerman et al., 2006). Studies performed prior to the study evaluated various procedures, which increased the time period available (Jungersen et al., 2005). These studies resulted in a new protocol in which whole blood collected in heparinised vacutainer tubes, was shipped by postal freight service and received at the laboratory the following day. At arrival, the whole blood was cultured with antigens with addition of co-stimulatory cytokine IL-12. Adding IL-12 to samples within 20 hours of collection rescues a weakened IFN- $\gamma$ response (Jungersen et al., 2005). This IL-12 potentiated IFN- $\gamma$ test was used for CMI analysis in the present study.

To each well in a 24-well culture plate (Greiner Bio-one, Heidelberg, Germany), $1.5 \mathrm{ml}$ blood was cultured with $10 \mu \mathrm{g} / \mathrm{ml}$ Johnine purified protein derivative (PPDj) antigens (National Veterinary Institute, Copenhagen, Denmark), $1 \mu \mathrm{g} / \mathrm{ml}$ superantigen staphylococcal enterotoxin B (SEB) and 
PBS (nil antigen) with addition of $10 \mathrm{U} / \mathrm{ml}$ recombinant IL-12 (a kind gift from Chris Howard and Jayne Hope, The Institute of Animal health, Compton, UK). Following stimulation for $18 \mathrm{~h}$ at 37 ${ }^{\circ} \mathrm{C} / 5 \% \mathrm{CO}_{2}$, the culture plates were centrifuged and approximately $0.8 \mathrm{ml}$ supernatant was harvested and stored in 96-well storage plates (Greiner Bio-One, Heidelberg, Germany) at $-20{ }^{\circ} \mathrm{C}$ until further analysis.

The antigen-specific IFN- $\gamma$ secretion in supernatants was determined by use of an in-house ELISA. MaxiSorp ${ }^{\mathrm{TM}}$ microtiter plates (Nunc, Roskilde, Denmark) were coated overnight at $4^{\circ} \mathrm{C}$ with 100 $\mu \mathrm{l} /$ well anti-bovine IFN- $\gamma \mathrm{F}(\mathrm{ab})_{2}$ monoclonal antibody (clone 6.19) (National Veterinary Institute, Copenhagen, Denmark) at a concentration of $0.3 \mu \mathrm{g} / \mathrm{ml}$. Subsequently, the wells were blocked for one hour with $200 \mu \mathrm{l} /$ well blocking buffer (PBS, 0.05\% Tween 20, 0.1\% Casein) and thereafter washed 5 times with washing buffer (PBS, $0.05 \%$ Tween 20). To each well $50 \mu$ l blocking buffer was added first, followed by $50 \mu \mathrm{l}$ supernatant or a two-fold standard dilution series. The reference standard was prepared from calf plasma stimulated overnight with $0.2 \mu \mathrm{g} / \mathrm{ml}$ SEB resulting in a known IFN- $\gamma$ concentration of $5,140 \mathrm{pg} / \mathrm{ml}$. The plates then incubated for one hour at room temperature with gentle agitation followed by 5 washings. Biotinylated secondary anti-bovine IFN$\gamma$ monoclonal antibody (clone 6.22) (National Veterinary Institute, Copenhagen, Denmark) was diluted in blocking buffer and $100 \mu \mathrm{l} /$ well was added in a final concentration of $1.76 \mu \mathrm{g} / \mathrm{ml}$ followed by one hour incubation at room temperature and 5 washings. Next, the wells incubated with $100 \mu \mathrm{l} /$ well ZyMAX horseradish peroxidase-conjugated streptavidin (ZYMED® Laboratories, Invitrogen, Carlsbad, CA, USA) diluted 1:10,000 in blocking buffer, for one hour at room temperature. Finally, the wells were washed 5 times and o-phenylenediamine dihydrochloride substrate (Sigma, St. Louis, MO, USA) was added and incubated in the dark for 20 minutes. The enzyme reaction was stopped by adding $100 \mu \mathrm{l} /$ well $0.5 \mathrm{M} \mathrm{H}_{2} \mathrm{SO}_{4}$ and the optical density (OD) was read at $490 \mathrm{~nm}$ with $650 \mathrm{~nm}$ reference subtraction. The level of IFN- $\gamma(\mathrm{pg} / \mathrm{ml})$ was calculated using 
linear regression on log-log transformed readings from the two-fold dilution series of the reference standard with known IFN- $\gamma$ concentration.

\subsubsection{Bacteriological culture of faecal samples}

The faecal specimens were decontaminated and cultivated as described previously (Nielsen et al., 2004). Briefly, samples were decontaminated in $4 \% \mathrm{NaOH} / 15$ minutes, $5 \%$ oxalic acid $+0.1 \%$ malachite green $/ 15$ minutes, neomycin sulphate + amphotericin B $(50 \mu \mathrm{g} / \mathrm{ml}) /$ overnight. Drops of decontaminated faecal samples were applied to four tubes containing Herrold's egg yolk medium (HEYM) (Difco/Becton Dickinson, Sparks, MD, USA). Following 8 and 12 weeks of incubation the cultures were inspected using an illuminated magnifier. All positive isolates were confirmed for the presence of IS900 insertion sequence by PCR.

\subsection{Interpretations of diagnostic procedures}

The ELISA test result was considered positive if $\mathrm{OD}_{\text {corrected }}\left(\mathrm{OD}_{\mathrm{C}}\right)$ was $\geq 0.3$ as used in the Danish paratuberculosis control programme (Nielsen, 2007). The IFN- $\gamma$ test was considered positive if IFN$\gamma$ levels in PPDj stimulated samples $\geq 1 \mathrm{ng} / \mathrm{ml}$. Furthermore, a sample needed a SEB-stimulated IFN- $\gamma$ level $>1 \mathrm{ng} / \mathrm{ml}$ and a PBS-stimulated IFN- $\gamma$ level $<1 \mathrm{ng} / \mathrm{ml}$ to be considered valid. Estimates of sensitivity and specificity for the IL-12 potentiated IFN-gamma test are not currently available and as such no fixed cut-points have been determined for the exact interpretation. The values for cut-points in this study have been decided based on our best guess. This guess has been based on levels of IFN-gamma in non-stimulated samples as well as the levels in PPDj stimulated samples in herds with different levels of Map exposure. Animals were considered FC-negative if all samples were negative at culture. 


\subsection{Statistical analysis}

Descriptive statistics were performed by grouping the 975 animals into eight groups based on results from FC, IFN- $\gamma$ and final ELISA status of the cow. The ELISA-profile for each cow within each group was plotted as a function of age at testing to check for unlikely values (data not shown), and the median corrected optical density $\mathrm{OD}_{\mathrm{C}}$ value was calculated in each group for descriptive purposes.

The generalised additive model (GAM) procedure in SAS v. 9.1 (SAS Institute, Cary, North Carolina, USA) were applied to explore the functional relationship between the outcome, $\mathrm{OD}_{\mathrm{C}}$, and the explanatory variables FC and IFN- $\gamma$. GAM is an extension of generalised linear models, in which variables are assumed to have a linear relationship with the outcome and are included additively. Generalised linear models use a so-called link function and are used to do regression modelling for non-normal data. In GAM, the usual linear function of a covariate is replaced with a smoothing function (Hastie and Tibshirani, 1991). Hence, in GAMs the variables are not assumed to have a linear relationship with the outcome. In the present analysis, we made predictions of the antibody-response as a function of age by semiparametric regression using GAM including the effect of FC and IFN- $\gamma$.

The model used was as follows:

$\mathrm{OD}_{\mathrm{C}}=\beta_{0}+\mathrm{I}_{i}+\mathrm{FC}_{j}+S($ Age $)$

where $\mathrm{OD}_{\mathrm{C}}$ was the corrected OD-value from the ELISA;

$\beta_{0}$ was the baseline value of the $\mathrm{OD}_{\mathrm{C}}$;

$\mathrm{I}_{i}$ was the fixed effect of IFN- $\gamma$ (where $i$ could be either positive or negative);

$\mathrm{FC}_{j}$ was the fixed effect of $\mathrm{FC}$ (where $j$ could be either positive or negative);

$S$ (Age) was the smoothing function of age in years, estimated using 4 degrees of freedom. 
Finally, the graphs showing predicted OD-values for different combinations of IFN- $\gamma$ and FC results were made. Because many cows did not become antibody positive, the above model was repeated while the final ELISA-status (E) was also included as a covariate. Thereby, the average antibody profile of the different groups can better be appreciated. 


\section{Results}

The distribution of samples within FC, IFN- $\gamma$ and E-groups is shown in Table 2, along with median $\mathrm{OD}_{\mathrm{C}}$-values of cows in each group. Parameter estimates for the model predicting the antibodyresponse as a function of age, with the effect of FC and IFN- $\gamma$ as covariates, are shown in Table 3. Predicted $\mathrm{OD}_{\mathrm{C}}$ was significantly affected by both FC $(\mathrm{p}<0.0001)$ and IFN- $\gamma(\mathrm{p}<0.0001)$. The parameter $\mathrm{FC}^{\div}$was negatively associated with predicted $\mathrm{OD}_{\mathrm{C}}$, whereas $\mathrm{IFN}-\gamma^{\div}$was positively associated, although to a minor degree, with predicted $\mathrm{OD}_{\mathrm{C}}$. The predicted $\mathrm{OD}_{\mathrm{C}}$ as a function of age at ELISA test for the four different groups of cows combining FC and IFN- $\gamma$ test are shown in Fig. 2. $\mathrm{FC}^{+}$cows had highest $\mathrm{OD}_{\mathrm{C}}$-values. Highest predicted $\mathrm{OD}_{\mathrm{C}}$ values were obtained for group $\mathrm{FC}^{+}$ IFN $-\gamma^{\div}$. The difference in $\mathrm{OD}_{\mathrm{C}}$ between IFN $-\gamma^{+}$and IFN- $\gamma^{\div}$was small $\left(\sim 0.02 \mathrm{OD}_{\mathrm{C}}\right.$-units $)$.The predicted $\mathrm{OD}_{\mathrm{C}}$ increased slightly with age at ELISA for all four groups of animals. Figure 3 illustrates predictions of $\mathrm{OD}_{\mathrm{C}}$ on cow level also including the final ELISA status. The highest average $\mathrm{OD}_{\mathrm{C}}$ values were predicted in the group including $\mathrm{FC}^{+} \mathrm{IFN}-\gamma^{+} \mathrm{E}^{+}$followed by the group $\mathrm{FC}^{+}$IFN $-\gamma^{\div} \mathrm{E}^{+}$. These two groups resulted in a higher predicted $\mathrm{OD}_{\mathrm{C}}$ response than any of the other groups presented in Figure 3. 


\section{Discussion}

We demonstrate that IFN- $\gamma$ test results obtained prior to first calving and FC status are correlated to antibody ELISA OD $_{\mathrm{C}}$ value at different ages after calving (Fig. 2). Surprisingly, the observed correlation was towards a negative IFN- $\gamma$ test predicting the higher OD value, however, although statistically significant, the IFN- $\gamma$ test result only slightly affected the future antibody status. Thus, many of the cows that tested IFN- $\gamma$ positive as calves never became ELISA positive and some IFN$\gamma$ test-negative heifers developed an ELISA response. MAP infections are by some considered incurable, but no evidence exists to support this. Cell-mediated immune responses may be able to eradicate MAP from some animals. Thereby, antibodies would never be expected to occur. Although the current data cannot prove this hypothesis, antibody profiles in Fig. 3 suggest that it may be a likely explanation. However, it is also likely that the animals with positive IFN- $\gamma$ and negative ELISA are merely controlling the infection, which will later erupt. It has previously been demonstrated that most animals shedding MAP will become ELISA-positive (Nielsen and Ersbøll, 2006). Therefore, both options are possible.

One of the problems with diagnosis of MAP is the lack of a reference test, whereby evaluation of diagnostic sensitivity and specificity becomes complicated. The IFN- $\gamma$ test is known to have a low specificity and hence a better correlation between IFN- $\gamma$, ELISA and FC may not be expected until this test has been further optimised. Comparison to a non-MAP mycobacterial antigen in the IFN- $\gamma$ test is often recommended, but in relation to MAP it is not straightforward to interpret (Jungersen et al., 2002). The IFN-gamma response to a non-MAP PPD, will not solely reflect the non-specific mycobacterial background production, but will also reflect paratuberculosis induced responses, because of high cross-reactivity. Denmark has been free from bovine tuberculosis since 1959, however, in a previous Danish study, several animals tested positive for bovine tuberculosis by IFN- $\gamma$ test and many animals reacted more strongly to avian PPD than to johnin PPD in known 
MAP infected herds, while this was not the case in MAP free herds (Jungersen et al., 2002). The sensitivity and specificity did not improve when the response to a non-MAP PPD was included and we chose to investigate responses only to PPDj in our further studies.

The predicted $\mathrm{OD}_{\mathrm{C}}$ in $\mathrm{E}^{+}$animals showed the highest increase at the age of 2.5 to 3.5 years and three groups became ELISA positive in this period. This is well in accordance with previous findings, that the highest probability of testing ELISA positive was from 2.5 to 4.5 years of age (Nielsen and Ersbøll, 2006). Sensitivity and specificity of the ELISA for detection of infected animals varies considerably with age. Sensitivity has been estimated to 0.06 for cows at 2 years of age and 0.50 at 5 years of age, while specificity was 0.997 at 2 years of age, and 0.93 at 5 years of age (Nielsen and Toft, 2006). A possible explanation for the relatively low specificity is that the $M$. plei absorbed ELISA using peroxidise-labelled anti-bovine $\operatorname{IgG}(\mathrm{H}+\mathrm{L})$ could detect $\operatorname{IgM}$ antibodies in milk samples because of common light chain of Ig. Non-specific ELISA results could have affected our results slightly. If non-specific reactions were considered random events, these would not impact the results. If non-specific reactions were non-random events, the results may have been inflated slightly.

The nature of the study was observational and herds were non-randomly selected. However, the 975 cows were included in the study were a random selection of the animals present in the herds at the time of sampling, thereby consisting of a representative population within these herds. The study only included MAP infected herds and hence the specificity of the tests was not evaluated. Another limitation to our study was that we observed relatively few $\mathrm{FC}^{+}$animals $(5.2 \%)$. Consequently, the distribution of $\mathrm{FC}^{+}$and $\mathrm{FC}^{\leftarrow}$ was skewed. There are several possible explanations for this very low number of $\mathrm{FC}^{+}$animals sampled from a dairy population in which paratuberculosis is common. For one, the sensitivity of faecal culture is on average low in animals tested below two years of age (0.05) but increases (0.21) at five years of age (Nielsen and Toft, 2006). In this study, a large 
proportion of the samples tested originated from cows in the age group two to three years $(48.7 \%)$. Second, the animals could be truly negative; however such a low prevalence is unlikely since the within-herd prevalence in Danish herds has been suggested to be 33\% (Nielsen et al., 2007). Several studies have evaluated diagnostic tests detecting CMI in response to paratuberculosis. These studies have been performed on experimentally infected cattle (Lepper et al., 1989; Collins and Zhao, 1995; McDonald et al., 1999) at various infection levels and in naturally infected herds (Huda et al., 2003; Huda et al., 2004; Nielsen and Toft, 2006). Experimental infection studies contribute with new knowledge of infection mechanisms, but it can be argued that the optimal study objects for evaluation of diagnostic tests are the target population in the natural environment. In the present study, we followed the same animals from calves to becoming adult cows.

For this study we used an IFN- $\gamma$ test protocol in which we co-stimulated day-old blood samples with IL-12, in order to rescue IFN- $\gamma$ production by Th1 cells in response to culture with MAP antigens. By using this protocol, we circumvent the major problems and logistics of stimulating blood samples in the laboratory within 8 hours of sampling at the farms. This is a major advantage in large studies and makes it possible to collect samples from farms outside the near vicinity of the laboratory. However, we face another problem since co-stimulation with IL-12 may induce nonspecific false positive reactions. False positive IFN- $\gamma$ production may be due to NK cells producing IFN- $\gamma$ in response to IL-12 (Jungersen et al., 2005). NK cells are part of the innate immune system and are observed at highest numbers in calves in which they constitute $5-10 \%$ of cells in peripheral blood (Kulberg et al., 2004). The impact of NK cells producing IFN- $\gamma$ without antigen-specific stimulation has not yet been described for this protocol.

Control for paratuberculosis in a herd involves breaking transmission routes by changing management practices. Most important is strict management of calves (Groenendaal et al., 2002). Calves are especially vulnerable and needs to be protected against exposure of faeces and milk from 
infectious cows. Breaking transmission routes will help controlling paratuberculosis over time and result in a lower prevalence. However, for fast eradication, an early diagnostic tool is necessary to identify infected calves, which may have been infected irrespective of the measures taken (Benedictus et al., 2008) before they become shedders of MAP and a risk to other animals. Such identification can be achieved by detection of the early CMI response in calves using IFN- $\gamma$ testing. The IFN- $\gamma$ test is in theory applicable at an early age and may be an important decision support tool for advisors in cattle practice. However, previous studies reported that the CMI responses measured by the IFN- $\gamma$ test fluctuate widely in young cattle, especially in calves younger than 6 months (Jungersen et al., 2002; Huda et al., 2003; Huda et al., 2004).

Further evaluation and optimisation of the IFN- $\gamma$ test using new and more specific antigens is necessary for diagnosis of paratuberculosis in young animals. In the present IFN- $\gamma$ test protocol we stimulated blood samples with PPDj which is a crude protein product that results in large variation in IFN- $\gamma$ response among animals. Evaluation of a cocktail of MAP specific recombinant antigens, as well as the significance of NK cells producing IFN- $\gamma$ in this in vitro assay remains to be explored. 


\section{Conclusion}

In the present study we investigated the association between IFN- $\gamma$, FC and milk antibody ELISA in paratuberculosis infected dairy herds. There was significant association between early IFN- $\gamma$ and subsequent FC status with occurrence of antibodies. However, the results indicate that only some IFN $-\gamma^{+}$animals will develop an antibody ELISA response, which suggest that cell-mediated immune responses control or eradicated MAP in many animals.

\section{Acknowledgements}

The authors thank the herd owners for access to collect samples repeatedly from their animals, the involved milk quality advisors and the local veterinary practitioners for careful collection of samples. In addition we thank Chris Howard and Jayne Hope, The Institute of Animal health, Compton, UK for the recombinant IL-12. The Danish Cattle Federation financed sampling and laboratory analyses via the CEPROS-II/7 project. 


\section{References}

Benedictus, A., Mitchell, R.M., Linde-Widmann, M., Sweeney, R., Fyock, T., Schukken, Y.H., Whitlock, R.H., 2008. Transmission parameters of Mycobacterium avium subspecies paratuberculosis infections in a dairy herd going through a control program. Prev. Vet. Med. 83, 215-227.

Chiodini, R.J., 1996. Immunology: Resistance to paratuberculosis. Vet. Clin. North. Am. Food. Anim. Pract. 12, 313343.

Chiodini, R.J., Vankruiningen, H.J., Merkal, R.S., 1984. Ruminant paratuberculosis (Johne's Disease) - the current status and future prospects. Cornell Vet. 74, 218-262.

Collins M.T., Zhao B.Y., 1995. Comparison of the commercial serum antibody ELISA, $\gamma$-interferon test kit, and radiometric fecal culture for early diagnosis of paratuberculosis in experimentally infected Holstein calves. In :Chiodini R.J., Collins M.T., Bassey E.O.E. (editors), Proceedings of the Fourth International Colloquium on Paratuberculosis, Cambridge, United Kingdom, July 17-21 1994, 67-76.

Groenendaal, H., Nielen, M., Jalvingh, A.W., Horst, S.H., Galligan, D.T., Hesselink, J.W., 2002. A simulation of Johne's disease control. Prev. Vet. Med. 54, 225-245.

Hastie, T.J., Tibshirani, R.J., 1991. Generalized Additive Models. Chapman \& Hall, London.

Huda, A., Jungersen, G., Lind, P., 2004. Longitudinal study of interferon-gamma, serum antibody and milk antibody responses in cattle infected with Mycobacterium avium subsp. paratuberculosis. Vet. Microbiol. 104, 43-53.

Huda, A., Lind, P., Christoffersen, A.B., Jungersen, G., 2003. Analysis of repeated tests for interferon-gamma (IFN- $\gamma$ ) response and faecal excretion for diagnosis of subclinical paratuberculosis in Danish cattle. Vet. Immunol. Immunopathol. 94, 95-103.

Jungersen G., Grell S.N., Clemensen A., Roust T., Huda A., Howard C.J., 2005. Interleukin-12 potentiation of the interferon-gamma test rescues day-old blood samples for diagnosis of paratuberculosis PPD specific cellular mediated immune response. In :Manning E.J.B., Nielsen S.S. (editors), Proceedings of the 8th International Colloquium on Paratuberculosis, Copenhagen, Denmark, August 14 -17 2005, 501-506.

Jungersen, G., Huda, A., Hansen, J.J., Lind, P., 2002. Interpretation of the gamma interferon test for diagnosis of subclinical paratuberculosis in cattle. Clin. Diagn. Lab. Immunol. 9, 453-460.

Kulberg, S., Boysen, P., Storset, A.K., 2004. Reference values for relative numbers of natural killer cells in cattle blood. Dev. Comp. Immunol. 28, 941-948. 
Lepper, A., Wilks, C.R., Kotiw, M., Whitehead, J.T., Swart, K.S., 1989. Sequential bacteriological observations in relation to cell-mediated and humoral antibody-responses of cattle infected with Mycobacterium paratuberculosis and maintained on normal or high iron intake. Aust. Vet. J. 66, 50-55.

McDonald, W.L., Ridge, S.E., Hope, A.F., Condron, R.J., 1999. Evaluation of diagnostic tests for Johne's disease in young cattle. Aust. Vet. J. 77, 113-119.

Nielsen, S.S., 2002. Variance components of an enzyme-linked immunosorbent assay for detection of IgG antibodies in milk samples to Mycobacterium avium subspecies paratuberculosis in dairy cattle. J. Vet. Med. B 49, 384-387.

Nielsen, S.S., 2007. Danish control programme for bovine paratuberculosis. BCVA 15, 161-168.

Nielsen, S.S., Ersbøll, A.K., 2006. Age at occurrence of Mycobacterium avium subspecies paratuberculosis in naturally infected dairy cows. J. Dairy Sci. 89, 4557-4566.

Nielsen, S.S., Kolmos, B., Christoffersen, A.B., 2004. Comparison of contamination and growth of Mycobacterium avium subsp. paratuberculosis on two different media. J. Appl. Microbiol. 96, 149-153.

Nielsen, S.S., Toft, N., 2006. Age-specific characteristics of ELISA and fecal culture for purpose-specific testing for paratuberculosis. J. Dairy Sci. 89, 569-579.

Nielsen, S.S., Toft, N., Jorgensen, E., Bibby, B.M., 2007. Bayesian mixture models for within-herd prevalence estimates of bovine paratuberculosis based on a continuous ELISA response. Prev. Vet. Med. 81, 290-305.

Olsen, I., Boysen, P., Kulberg, S., Hope, J.C., Jungersen, G., Storset, A.K., 2005. Bovine NK cells can produce gamma interferon in response to the secreted mycobacterial proteins ESAT-6 and MPP14 but not in response to MPB70. Infect. Immun. 73, 5628-5635.

Ott, S.L., Wells, S.J., Wagner, B.A., 1999. Herd-level economic losses associated with Johne's disease on US dairy operations. Prev. Vet. Med. 40, 179-192.

Robbe-Austerman, S., Krull, A.C., Stabel, J.R., 2006. Time delay, temperature effects and assessment of positive controls on whole blood for the gamma interferon ELISA to detect paratuberculosis. J. Vet. Med. B 53, 213-217.

Stabel, J.R., 2000. Transitions in immune responses to Mycobacterium paratuberculosis. Vet. Microbiol. 77, 465-473.

Sweeney, R.W., 1996. Transmission of paratuberculosis. Vet. Clin. North. Am. Food. Anim. Pract. 12, 305-312.

Toman, M., Faldyna, M., Pavlik, I., 2003. Immunological characteristics of cattle with Mycobacterium avium subsp. paratuberculosis infection. Vet. Med. 48, 147-154. 
Table 1. Description of the 18 herds included in the study: herd size and production level for two periods

\begin{tabular}{ccccc}
\hline & \multicolumn{2}{c}{$2003-2004$} & $2^{2006-2007}$ \\
\hline Herd & Cow years $^{1}$ & ${\text { ECM }\left(\mathrm{kg} / \text { cow year }^{1}\right.}^{1}$ & Cow years $^{2}$ & ECM (kg/cow year $)^{2}$ \\
\hline 1 & 209.4 & 10478 & 227.5 & 10004 \\
2 & 203.6 & 8364 & 345.3 & 9070 \\
3 & 132.2 & 10838 & 178.0 & 10342 \\
4 & 104.8 & 8510 & 101.7 & 10035 \\
5 & 136.2 & 8887 & 133.3 & 9531 \\
6 & 129.6 & 9519 & 135.7 & 9935 \\
7 & 67.2 & 7644 & 76.4 & 7290 \\
8 & 130.2 & 11115 & 200.0 & 9093 \\
9 & 110.1 & 11392 & 117.7 & 11858 \\
10 & 117.6 & 11302 & 170.1 & 11430 \\
11 & 117.9 & 9012 & 359.8 & 9264 \\
12 & 95.5 & 8408 & 117.4 & 8646 \\
13 & 120.8 & 9719 & 138.2 & 9848 \\
14 & 122.9 & 9076 & 166.7 & 10358 \\
15 & 71.5 & 8717 & 87.0 & 8866 \\
16 & 157.6 & 8757 & 151.2 & 9694 \\
17 & 128.1 & 9040 & $*$ & - \\
18 & 84.0 & 9892 & $*$ & - \\
\hline
\end{tabular}

$\mathrm{Kg}$ ECM was estimated from the milk yield control scheme carried out in the herds 11 times per year

${ }^{1}$ In the period October 1, 2003 to September 30, 2004

${ }^{2}$ In the period October 1, 2006 to September 30, 2007

* Ceased production April 2005

Table 2. Distribution of 5545 milk samples tested using ELISA from 975 Danish dairy cows included in the study. Observations are cross-tabulated by age of the cows from which the milk sample samples were obtained. Number given was no. of samples in the group. Values in parentheses represent median predicted optical density $\left(\mathrm{OD}_{\mathrm{c}}\right)$ value of cows in the group.

\begin{tabular}{|c|c|c|c|c|c|c|}
\hline \multirow[t]{2}{*}{$\mathrm{FC}$} & \multirow[t]{2}{*}{ IFN- $\gamma$} & \multirow[t]{2}{*}{ ELISA $^{\#}$} & \multicolumn{4}{|c|}{ Age group } \\
\hline & & & $\leq 2$ years & 2-3 years & 3-4 years & $>4$ years \\
\hline \multirow[t]{4}{*}{ Negative } & Negative & Negative & $47(0.00)$ & $942(0.00)$ & $758(0.00)$ & $291(0.00)$ \\
\hline & & Positive & $53(0.02)$ & $311(0.01)$ & $185(0.20)$ & $110(0.30)$ \\
\hline & Positive & Negative & $23(0.02)$ & $1087(0.00)$ & $837(0.00)$ & $219(0.00)$ \\
\hline & & Positive & $2(0.19)$ & $206(0.03)$ & $149(0.22)$ & $37(0.40)$ \\
\hline \multirow[t]{4}{*}{ Positive } & Negative & Negative & $4(0.06)$ & $21(0.00)$ & $16(0.00)$ & $3(0.10)$ \\
\hline & & Positive & 0 & $37(0.12)$ & $29(0.33)$ & $13(0.40)$ \\
\hline & Positive & Negative & $1(0.05)$ & $52(0.01)$ & $29(0.00)$ & $3(0.00)$ \\
\hline & & Positive & $4(1.45)$ & $47(0.11)$ & $25(0.60)$ & $4(0.80)$ \\
\hline
\end{tabular}

$\mathrm{FC}=$ Faecal culture test; IFN- $\gamma=$ Interferon-gamma test

\# ELISA-status was determined from analysis of all available ELISA results of each animal. 
Table 3. Parameter estimates of interferon gamma (IFN- $\gamma$ ) and faecal culture (FC), for the model predicting antibody response expressed as corrected optical density $\left(\mathrm{OD}_{\mathrm{C}}\right)$ value as a function of age.

\begin{tabular}{lrrr}
\hline Parameter & Parameter estimate & Standard error & P-value \\
\hline Intercept & 0.1076 & 0.0140 & $<0.0001$ \\
IFN- $\gamma$ positive & 0 & - & - \\
IFN $-\gamma$ negative & 0.0208 & 0.0045 & $<0.0001$ \\
FC positive & 0 & - & - \\
FC negative & -0.1730 & 0.0102 & $<0.0001$ \\
\hline
\end{tabular}




\begin{tabular}{|l|l|l|l|l|l|l|l|l|l|l|l|l|}
\hline & IFN- $\gamma$ & & Calvin & & E & E & E & FC & E & Calvin \\
\hline
\end{tabular}

Life of cow

Fig 1. Diagram showing sample collection from an animal in the study. Blood samples for interferon gamma (IFN- $\gamma$ ) tests were collected from cattle 15 to 24 months of age. After calving, milk samples for ELISA (E) $(\mathrm{sp}=0.96)$ were collected 4 times annually and faecal samples (FC) were collected once every 12 months.

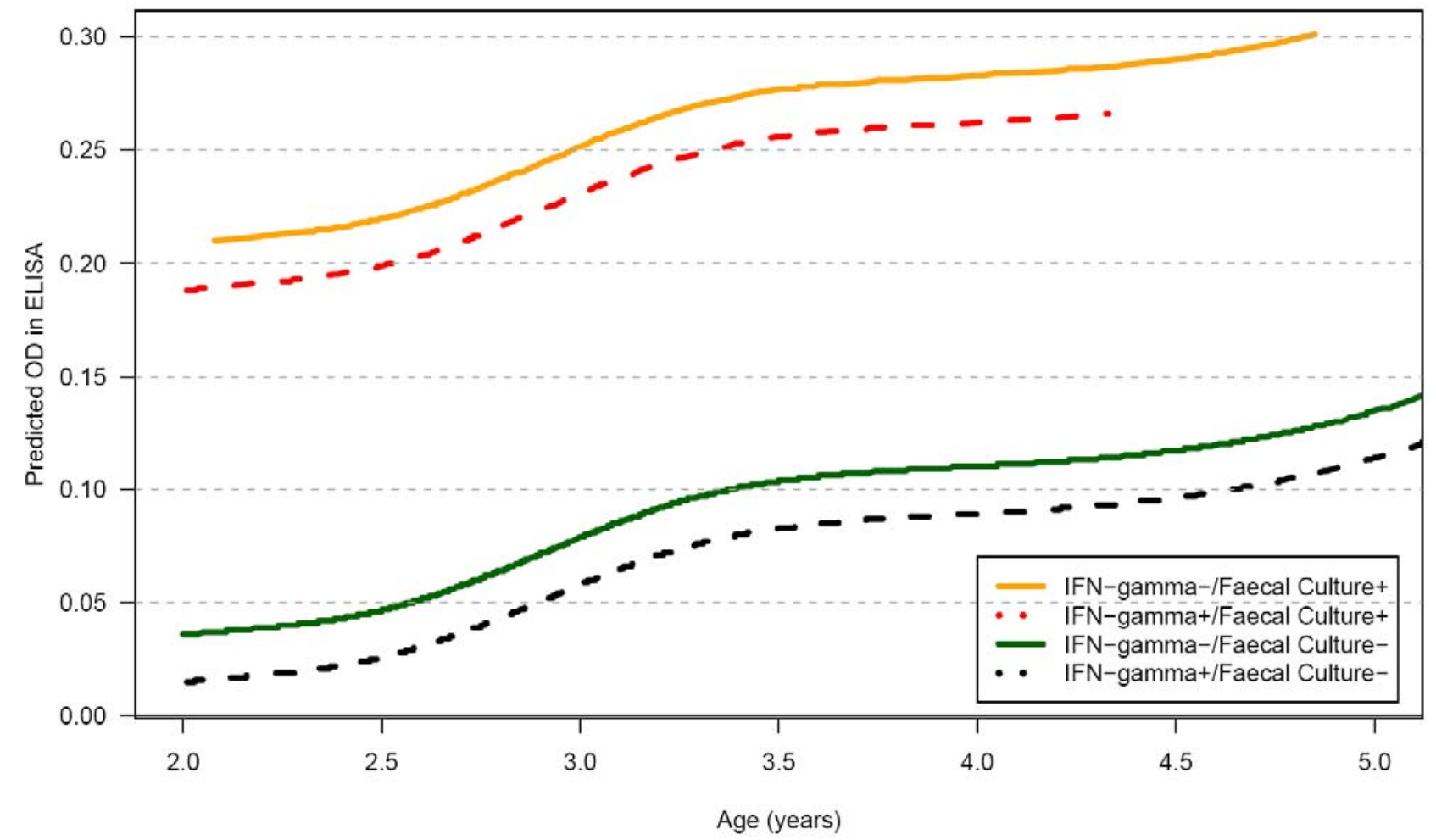

Fig 2. Predicted corrected optical density $\left(\mathrm{OD}_{\mathrm{C}}\right)$ value in Mycobacterium avium subsp.

paratuberculosis milk antibody ELISA of cows, at ages from 2 to 5 years, based on previous interferon gamma (IFN- $\gamma$ ) and faecal culture (FC) results. Predictions are shown for four groups of cows: IFN $-\gamma^{\div} \mathrm{FC}^{+}, \mathrm{IFN}-\gamma^{+} \mathrm{FC}^{+}, \mathrm{IFN}-\gamma^{\div} \mathrm{FC}^{\div}$and IFN $-\gamma^{+} \mathrm{FC}^{\doteqdot}$ based on data from 18 Mycobacterium avium subsp. paratuberculosis infected dairy cattle herds. 


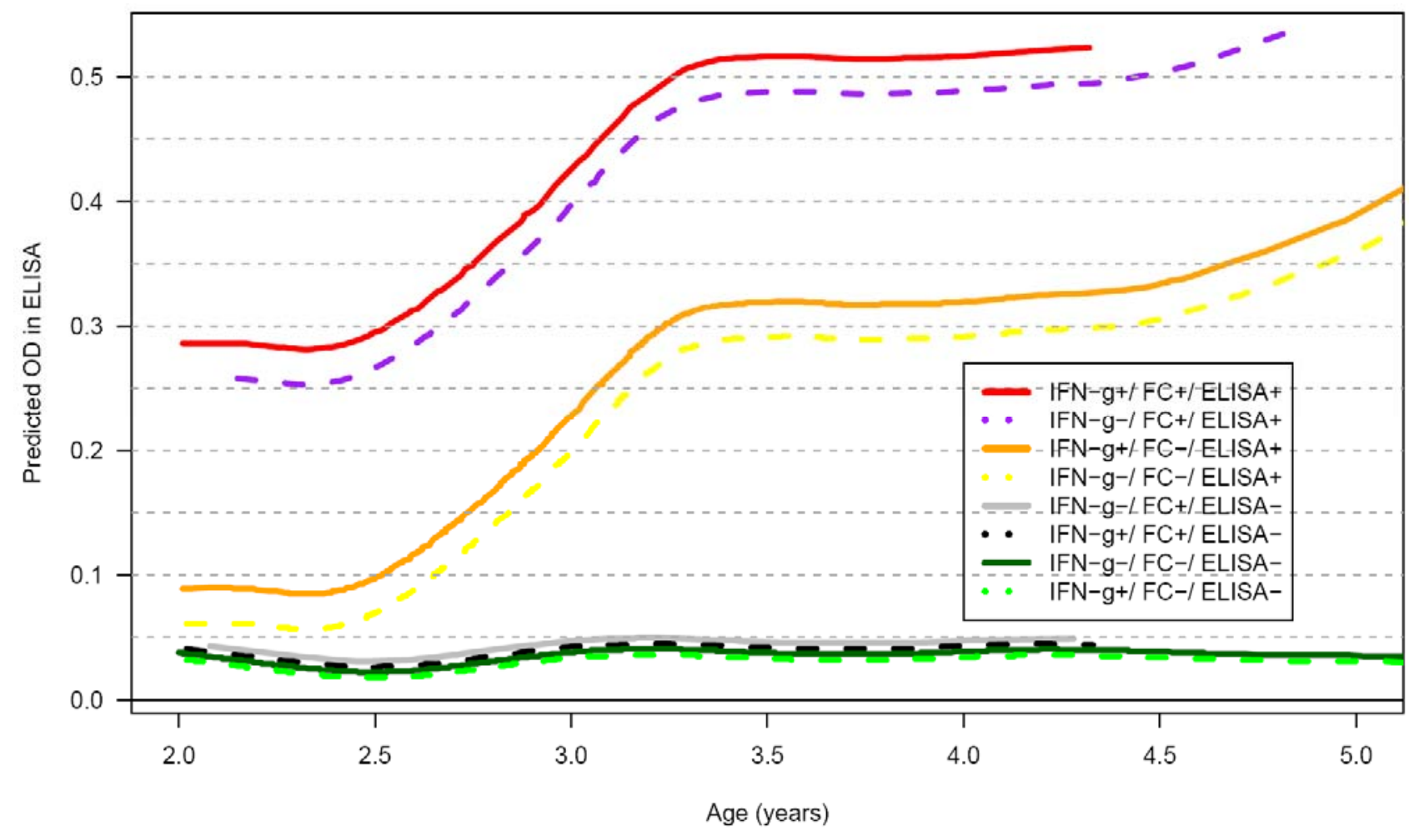

Fig 3. Predicted corrected optical density $\left(\mathrm{OD}_{\mathrm{C}}\right)$ value in Mycobacterium avium subsp.

paratuberculosis milk antibody ELISA for cows, at different ages from 2 to 5 years of age stratified for animals becoming ELISA ${ }^{+}$and ELISA $\div$. Predictions are shown for 8 groups of cows: IFN-

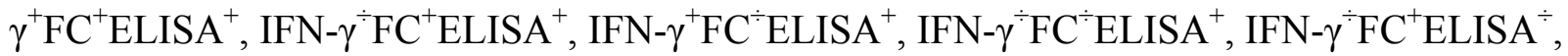

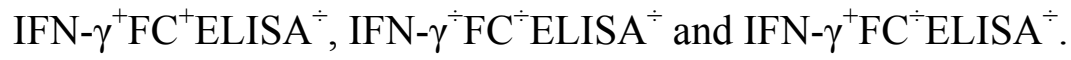

